\title{
Analytical Strength of First Year Student's Academic Performance at University
}

\author{
Jacob M Selesho \\ Faculty of Management Sciences, Vaal University Technology, \\ Vanderbijpark. South Africa \\ E-mail:jmselesho@gmail.com
}

\section{Doi:10.5901/mjss.2013.v4n3p371}

\section{Abstract}

The study of analytical strengths of first year academic achievement in teacher education admission as a response to the growth in the demand and quality of teachers that are trained have remained largely unexplored, especially the employment rate.This paper reports on the findings of a research conducted on the performance of students in teacher education programmes who enrolled for the first time in 2004. The key issue examined in the paper is whether the selection process used for admitting students into Teacher Education programmes have a significant contribution to the academic success of the students, their success in career prospects and employment opportunities and mainly gender issues. The assumption made is that students who have performed better in grade 12 are likely to complete their qualification in the designated time and perform better in the workplace. In an effort to widen understanding regarding the factors that predict the performance of Teacher Education students, prior academic achievement results in the form of Grade 12 were examined.89 students admitted to the Central University of Technology, Free State in teacher education at the beginning of the 2004 academic year were sampled for the study. Data concerning drop-out, study progress and graduation statistics were derived from the student administration and examination section. Data about career development were obtained from interviews with graduates, School Management Teams and learning facilitators. The results reveal that grade 12 results (Swedish points) had no significant effect on drop-out rate. High Swedish points above a 25 score were associated with significantly less time before graduation, better career progression and better productivity in the teaching subjects. Gender differences were found in the study duration and career progress. Female students graduate earlier and have a better chance of climbing the ladder in terms of career progress.

Keywords: Analytical, Strengths, Performance, Employment, Study Success

\section{Introduction}

Academic success has become the order of the day in most Higher Education institutions (HEl's) particular at the pre-graduate level where admission is based on high school results. Although schooling system has been blamed for poor student's preparations at the high school level, it has assumed that this poor preparation will influence the academic progression as they continue the academic journey at the HEl's. The question of poor performance at universities is largely attributed to inadequate schooling by most, if not all. In the light of inadequacies in schools, HEl's in some countries, require students to write entrance tests to be admitted into the career qualification of their choice.

It is of particular concern that Grade 12 alone cannot be trusted as an indicator for predicting the success of learners at South African Higher Education Institutions (SAHEs), particularly in the Teacher Education programme. It is against this backdrop that the current article intends to interrogate the concerns expressed by number of HEls with regard to the use of Grade 12 results as analytic strength to measure the student's performance at first year level.

It is the intention of this paper to discuss the analytical strength of the first year students particular their progression and employment opportunities.

\section{Theoretical Scaffold}

National Senior Certificate system is producing students who do not easily do well in higher education (HE). The Department of Basic Education (DBE) study on graduation rates at SAHE indicated that only 30 per cent of first-time entering students had graduated after five years of study. By the end of 2004 (five years after entering) 56 per cent had left their original institutions and only about 14 per cent were still in the system (Nel, Troskie-de Bruin \& Bitzer, 2009: p974-975). 
Many countries have recognised the shortage of qualified teachers as a serious problem in the field of education. Countries such as South Africa, the USA, the UK, Canada and Australia, find it difficult to recruit an adequate number of secondary school students to enter the teaching profession, science and mathematics students with graduate degrees, in particular (Wang, 2004). However, in the past, when teacher-training colleges had the exclusive right to train teachers in South Africa, there was no difficulty in recruiting academically able students to teacher colleges and training them.

Accelerated training programmes in Teacher Education are growing rapidly. In 2006, there were 386,595 teachers employed by the Department of Education in South Africa (DoE, 2006: p8). The Educator Demand and Supply report suggests that South Africa will experience a shortage of teachers in the coming years. The report points out that there is an overall misalignment between supply and demand in terms of the specific education phases and subject areas, with shortages being acute in Mathematics, Science and Technology, Arts and Languages and in the Foundation and Intermediate phase. In 2010, 7343 students were enrolled for teacher education programmes in 15 universities that were participants in the Higher Education Quality Committee (HEQC) review. Emanating from the HEQC review it was reported that the general pattern of admission is that the students who meet the admission requirements for the programme are accepted without professional screening. In many cases, the Bachelor of Education has lower entrance requirements than any other qualification in most universities. To a large degree alternative routes have been created for admission purposes through senate, as universities want to increase the number of teachers in response to the national outcry on teacher demand and supply.

\subsection{Predictive Validity of Admission requirements entrance}

University admission practices, including those for graduate level leadership preparation programmes, have evolved over time. In the 1920s, a shift away from student preparation towards the prediction of student success occurred. Many tests were developed during this period to be used as a basis for student admission decisions (Mohammadi, 2009: p59). Admissions practices during this period were developed to adhere to the philosophy that HEl's should provide expanded access for all academically able students (Bohler, 2000; p14). The 1980s began a period that has been termed the 'pragmatic era'. Shifting conditions, including a decline in the population of academically able college-age students, the need to better understand the qualities and needs of diverse student populations, and the legal mandates for valid, reliable, and equitable admission criteria marked this period. In the last 20 years, two major changes in admission practices have occurred. A greater emphasis on student recruitment activities began in the mid-1980s (Dooey, 1999). Recruitment efforts during this time reflected the other major change during this period, a shift towards "fitting the college to the characteristics and needs of the students rather than the other way around". The trend toward "student consumerism' caused higher education institutions to change the way they do business (Mohammadi, 2009: p60).

The nature of the admission requirement, in fact, dictates that educational experts discover to what extent admission tests can predict the academic success of the students in future. Many studies have examined the predictive value of admission tests to academic institutions. Huong as cited by Mohammadi (2009: p62) found a similarity of construct between the test battery and Grade Point Average (GPA) among Vietnamese students sponsored by the Australian Agency for International Development (AusAID) at Australian universities. In her research to investigate the predictive validity of test battery as an indicator of future academic success, Dooey (1999) failed to offer conclusive evidence about the validity of test battery as a predictor of academic success. Mohammadi (2009: p61) also indicated that there was a significant, positive relationship between both undergraduate admission and general test scores with first-year graduate grades in veterinary medicine. In his study he reports on the predictive validity for the first-year examination performance at the University of Cambridge. Emery (2007: p6) could not find any relationship between the two variables and concluded that the reasons for poor performance at university are many and states "An entrance test can only predict those who can: not necessarily those who will". Others also had the same results. A study by Sireci and Talento-Miller (2006: p308) looked at the predictive value of the Graduate Management Admission Test (GMAT) and GPA data from 11 graduate management schools. They found the predictive value of GMAT analytical writing scores as relatively low, accounting for only about $1 \%$ of the variation in the graduate GPA, after accounting for undergraduate GPA and GMAT scores (Shepard,1997: p24).

\subsection{Selection process in Teacher Education Programs}

According to Kotze and Griesel (2008:61), problems concerning the selection of students and its validity are not only particular to South Africa, but are a worldwide phenomenon. Most teacher education programmes use students' Grade 
12 results' points as a criterion for admission (Riggs \& Riggs, 1991). The use of the Swedish scale point is still the dominating factor in admitting students in this type of programme. In some instances, the programmes combine the Swedish Scale point generated from Grade 12 results together with the psychometric test. At no stage is the applicant required to describe relevant experiences and why he/she is interested in teaching Smith and Hambleton (1990: p7-9) asked to produce letters of reference or ratings being available of the applicant's performance in an interview (Sireci, \& Talento-Miller, 2006: p308). In the United States, standardised test results are commonly used, with results from specific pre-requisite education courses also being utilised. Finally, for applicants intending to become high school teachers, most consecutive programmes require university-level coursework in the subject areas to be taught.

Grade 12 Swedish scale ratings are the most widely used criterion for admission to teacher education programmes. It is generally believed to measure academic ability and so is thought to predict success in the instructional parts of the programmes. However, a more important reason for its popularity as a criterion is most likely its ready availability from students' statement of results and its use by other university programmes. As Smith and Hambleton (1990:p7-9) note "The practice conforms to the conventional academic practice; rejected applicants rarely challenge it". Past success is usually used as an indicator of future success and few have found a weakness with this argument. In Canada most Teacher Education programmes use GPA as a criterion (Smith \& Pratt, 1996). However, although it is the most used criterion for admission into Teacher Education programmes, research has shown a weak relation between GPA and performance in these programmes (Salzman, 1991).

The second most widely used criterion for entrance into Teacher Education programmes is an applicant profile, consisting typically of written responses to specific questions about relevant experiences and interest in teaching. Such a profile includes much of the same information that could be elicited in an individual interview. The responses may be reviewed by the Teacher Education programme for evidence of appropriate preparation and genuine interest in teaching or for evidence of the student's unsuitability for the profession (Tait, van Eeden \& Tait, 2002: p177-182).

In Ontario, all but one Teacher Education programme uses some form of profile or essay response for screening applicants (Salzman, 1991).

The interview provides a unique opportunity for the Teacher Education programme to gather information about an applicant's language proficiency, attitudes and interpersonal skills, in addition to information similar to that which could be gleaned from a written profile. Some Ontario Teacher Education programmes use interviews as part of their admission process (Smith \& Hambleton, 1990: p8-9).

Wilcox (2005: p19-22) suggests that interviews are necessary to ensure the selection of applicants who understand the moral and ethical dimensions of teaching, because the applicants "cannot develop a value-based and attitudinal perspective for enculturating the young within the time frame 'of the interview' unless they are clearly predisposed to those ends" (p. 19). In a written profile, in contrast, it is possible for the applicant to copy materials from other sources or to obtain help in preparing his/her responses. However, Wilcox (2005: p19-22) concludes that the interview process is not sufficient either to determine whether applicants possess the desired attributes or to assess their ability.

Applicants for preparation as high school teachers, however, should provide proof of adequate knowledge of the subject areas they intend to teach. Often, this requirement is met by providing a university Grade 12 statement of results showing the marks obtained in completion of Grade 12. Smith and Hambleton (1990: p7-9) recommend that high school teachers have a minimum requirement of six semester courses in their major teaching area. More recently, Sireci and Talento-Miller (2006: p305-307) has suggested that the content of the subject at high school should be considered and that university academic departments should be held responsible for the content knowledge of primary and high school teachers in their disciplines.

\section{Methodology}

Data were collected from the Central University of Technology, Free State from students enrolled in 2004 academic year for Teacher Education programmes. The admission requirement was based on the form of Swedish scale ratings only, no psychometric test results were used further as a support tool to Swedish scale. Student-teaching grades were available for 89 initial professional teaching applicants (IPET). The IPET sample consisted of students with the following majors: 55, Economics and Management Sciences; 17, Natural Sciences; 9, Computer Sciences and Technical Education; 8 programmes. Of the 89 participants, $65 \%$ were coded as male and $35 \%$ were coded as female.

\subsection{Procedure}


The graduation throughput database of 2008 was used as a correlation with Grade 12 results of 2004 when these students were admitted. The intention was to determine if there is any gap as a result of Grade 12 performances; these high quintile learners and their performance in four years. These correlations can be interpreted as indicators of the performance measurements towards completing the degree in four years.

Accordingly, we examined individual student Grade 12 results and developed Swedish ratings to determine their admission status and corresponding first-year results. This assisted in determining the predictive validity; the student teaching subject was also taken into consideration. The focus was on the student admitted in 2004 with the intention of graduating in 2008 as the B.Ed is a four- year degree. Finally, we compared the graduation rates among males and females and the different programmes.

The researcher conducted surveys in order to gather qualitative and quantitative sources of data that would shed more light on this group of students admitted into teacher education programmes. The purpose of the survey was to gauge whether the results of Grade 12 are really able to predict the completion of studies and also assist in determining the success of students.

\section{Findings and Discussion}

89 questionnaires were received from first-year students; the findings are presented and discussed under the various themes in the study.

\subsection{Student admission}

The criteria used in admitting the class of 2004 was purely on the Swedish scale ratings generated from Grade 12 results. This method was considered the only reliable predictor to determine the student's success at the university level. The study did not focus on the admission requirements as set by the university; however, a more attention was paid to the admitted students' points.

The admission requirements were based on the calculation of the subject levels and admitted students were regarded as potential candidates to complete the degree within a four-year period. A minimum of 20 points was expected in order to admit the students and this was regarded as a predictor for cognitive ability to complete the degree. Furthermore, it would give the university the confidence that the right student had been selected for career opportunities. The students should be admitted with the necessary credibility to graduate with the degree. To perform our analysis, we used the 89 student admission Swedish points as a predictor for university success. Figure 1 gives an indication of the admission ratings of students.

Figure 1: Swedish Scale ratings of admitted students in B.Ed: FET in 2004

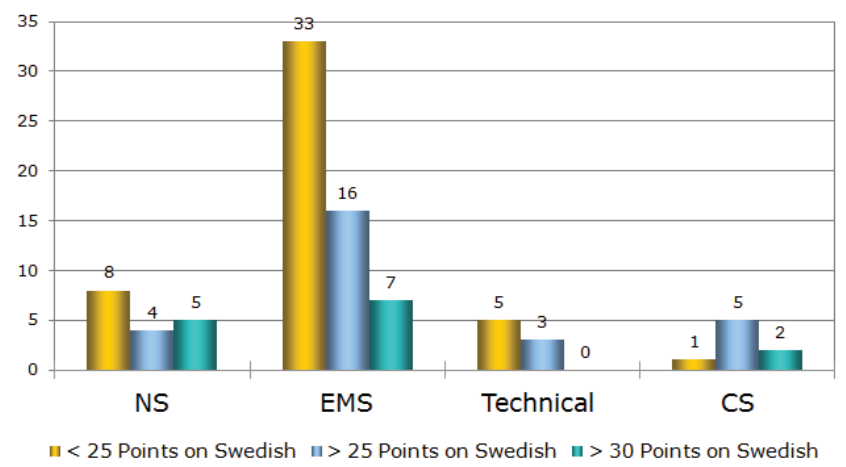

In order to be admitted for a teacher education programme a minimum of 20 points should be obtained in the Grade 12 results. The only screening process was the Swedish ratings calculations; no interviews and psychometric test were written as part of the admission screening. In most cases, universities admit students that score the highest points in the screening process. Secondly, in order to meet this requirement, students should have subjects relating to the degree for which they wish to enroll. 
From figure 1 a total of 89 students admitted in 2004, the study revealed that 14 students with Grade 12 ratings were above 30 points on the Swedish scale. In addition to this, the remaining student ratings were as follows: 28 student ratings were above 25 points just below 30 points on the Swedish scale, while the majority (47) ratings were above 20 points but below 25 points on the Swedish ratings.

There are several possible explanations for this finding; essentially, the mismatch between high school graduation requirements and university admission requirements has been closing, without forcing more students to drop out.

\subsection{Graduation output}

To calculate graduation rates, we used the admission Grade 12 Swedish ratings as an indicator to determine the success of teacher education. The Grade 12 ratings assist in estimating the number of students who entered a university for the first time in 2004 and dividing the resulting number into the number of students who could actually graduate with a B.Ed degree.

The enrollment data provided by the student administration were used to determine the number of student who entered the B.Ed: Further Education and Training Programme in 2004. This database included the total Swedish scale used by the students on enrolment counts. The intention of the research was to determine the graduation rate based on the number of students who were admitted and secondly, to gauge the Swedish scale on enrolment. The study concentrated only on students who were admitted for the first time into teacher education in the 2004 academic year. The study excluded students who were repeating their studies.

To estimate the number of students who should have graduated with the qualification at the end of the fourth year, a monitoring instrument was put in place firstly, to track first entrance students and to determine any dropouts during the course. The study revealed that there was a change in the total cohort admitted and this predicted the ultimate graduation rate. The graduating figure would have been 89 students who would have to graduate with the B.Ed: FET Specialisation at the end of the fourth year and in this case, the university would have a graduation rate of $100 \%$. From a total of 89 students only 40 students graduated.

The study followed a cohort of students for a period of four years, from when they entered university for the first time until they graduated. While students who took longer than four years to graduate were excluded, they were not seen as possible predictors for success. Thus, as long as there was not a substantial change in the number of students in each cohort who graduated in more than four years, those students would be included as graduates in our graduation rate calculation. Table 1 is the B.Ed graduation rates and it will outline the graduation throughput per programme.

Table 1: B.Ed: Graduation Rates

\begin{tabular}{|c|c|c|c|c|c|c|c|}
\hline $\begin{array}{c}\text { Admitted } \\
\text { N/S }\end{array}$ & $\begin{array}{c}\text { Graduates } \\
\text { N/S }\end{array}$ & $\begin{array}{c}\text { Admitted } \\
\text { Technical }\end{array}$ & $\begin{array}{c}\text { Graduates } \\
\text { Technical }\end{array}$ & $\begin{array}{c}\text { Admitted } \\
\text { EMS }\end{array}$ & $\begin{array}{c}\text { Graduates } \\
\text { EMS }\end{array}$ & $\begin{array}{c}\text { Admitted } \\
\text { C/S }\end{array}$ & $\begin{array}{c}\text { Graduates } \\
\text { C/S }\end{array}$ \\
\hline $17(100 \%)$ & $15(88 \%)$ & $8(100)$ & $3(38 \%)$ & $55(100 \%)$ & $19(34 \%)$ & $9(100 \%)$ & $3(33 \%)$ \\
\hline
\end{tabular}

Table above compares the graduation rates per programme for the class of 2004 with the actual number of students who enrolled for the programme for the first time in 2004. The results of this comparison indicate that there were not a large number of students who graduated from the B.Ed. Overall, the estimate was that more than $60 \%$ of students enrolled would graduate at the end of the fourth year, which is just under 100 , the number of students who actually enrolled for teacher education at the university for the first time were 89.

Because analyses were based on the relative standing of predictors and the criteria used for admission to different programmes, possible differences in graduation statistics would be visible. Graduation rates vary considerably among the various programmes. Table 1 further outlines the different programmes and ranks the programmes on their overall graduation rates. B.Ed FET Natural Sciences specialisation has the highest graduation rate among the different programmes at $88 \%$. It is followed by the Technical Education programme with 38\%; Economics and Management Sciences sat at $34 \%$ and lastly, Computer Sciences programme at 33\%. These graduation rates represent students who were admitted in 2004 for the first entrance to the university and graduated in 2008 as the B.Ed programmes run over a four-year period.

These results imply that increasing the number of students who should graduate requires improving the admission requirements. 
Figure 2: Admission requirements vs graduation throughput

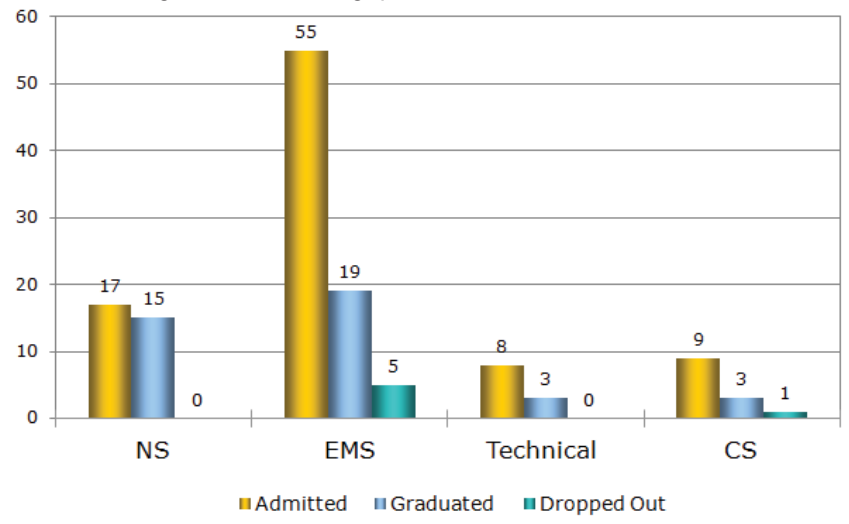

Figure 2 report on the Grade admission and the graduation rates in comparison with the admission points. From a total of 40 students who graduated, 28 students achieved above 25 on the Grade 12 Swedish ratings; the remaining 12 students achieved between 21 and 24 on the Swedish ratings. Although more than 89 students were admitted, only 40 managed to graduate with a degree. This pass rate was far below the school of teacher education graduate target for 2008 and much lower than the Central University of Technology graduation target. The table also shows that from the majority of students who were admitted with fewer than 25 points from Grade 12, only minority graduated. The study reveals that students who were admitted with lower ratings on the Swedish scale were much less likely to graduate with a degree in the designated time.

\subsection{Gender Ratio}

Table 2 of the study shows the gender and composition of the students admitted. These are important factors in determining the perceived difficulties in graduating encountered by students at university in terms of gender.

Table 2: B.Ed: Graduation Rates by Gender

\begin{tabular}{|c|c|c|c|c|}
\hline Admitted Males & Graduated Males & Admitted Females & Graduated Females & Total Graduates \\
\hline $56(65 \%)$ & $22(38 \%)$ & $33(35 \%)$ & $18(56 \%)$ & 40 \\
\hline
\end{tabular}

Table 2 shows the students' demographic profile of gender with regard to admission and total graduates. Typically of a programme in a school of teacher education, the majority of the students were male (65\%), while $35 \%$ were female. The gender differences observed in this study showed that although the admission male population was high among the number of students admitted, the process was reversed in the graduation rates. The highest numbers of graduates were female $56 \%$, while the male rate was $39 \%$. Among the 56 admitted male students only 22 managed to complete their studies within the time-frame of four years. This is a smaller number compared with the total number of female students admitted of 33, of which 18 managed to complete their studies in the allocated time. There was a significant difference in gender performance; females performed better than their male counterparts. This statement is supported by the graduation rates when aligned to the admission per gender.

\section{Conclusion}

Academic scores have generally been found to be better predictors of study success than non cognitive criteria. Several factors contribute to the relationship between academic scores and study success. Admission to all teacher education programmes in South African universities is determined by weighted Swedish scale points as per the Grade 12 performance. Admission decisions made are important because several studies suggest that only approximately $50 \%$ of the applicants admitted ever complete their studies (Dooey, 1999). Consequently, an inadequate selection decision on the part of the university is likely to affect the university throughput. Indeed, a major task facing academics is to admit the 
right students who meet the minimum requirements. There should be a balance on admitting students on a low quintile and high quintile of the Grade 12 results.

Our results have several lessons for policymakers and university administrators. Firstly, provision should be made for a more accurate estimate of the admission rate and university-readiness rates. Far fewer students graduate from universities to fill the teaching positions available, while expectations are high from the Department of Basic Education. Only 45\% of the students who were admitted to the Teacher Education programme in 2004 completed their degree as the other $55 \%$ who were admitted with lower points on the Swedish ratings to graduate.

The findings further indicate that such low graduation rates can be attributed to the poor achievement of students in Grade 12 and therefore imperative that the high quintile admission be used as a predictor for university success. Students who have performed in the higher quintile in Grade 12 are likely to complete their degree in allocated time. Universities should begin to introduce support programmes in order to assist students in the lower quintile. Teacher Education uses different admission procedures, based mainly on cognitive and non-cognitive criteria.

Finally, results imply that we cannot increase participation in the four-year degree without addressing the problems of high schools. Our results indicate that there are not a large number of students who are eligible for admission to university. This means that substantially increasing university participation in teacher education programme means increasing the number of students leaving the system with the skills necessary even to be considered for admission. Thus, reforms that focus on making university attendance less burdensome for those who already have the skills, such as increased financial aid, cannot substantially increase university enrolment in themselves. Increasing university enrolment requires increasing the number of students who have the skills necessary to move on to the next academic level.

\section{References}

Bohler, N (2000). The transformation of education with special reference to law students at a historically disadvantaged tertiary education. 14(1), 12-18.

Bloch, G. (2009). The toxic mix whats wrong with South Africa Schools and how to fix it. Tafelberrg first edition. Cape Town

Council on Higher Education: (2003). The state of Private Higher Education in South Africa. Pretoria: CHE.

Council on Higher Education: (2006). A case for Improving teaching and learning in South Africa Higher Education. Pretoria: CHE.

Council on Higher Education: (2007). A case of improving teaching and learning in South Africa ational Review of Academic and Professional Programmes in Education. Pretoria: CHE.

Council on Higher Education: (2010). National Review of Academic and Professional Programmes in Education. Pretoria: CHE.

Cosser, M. (2009). Studying ambitions: Pathways from Grade 12 and the factors that shape them. Cape Town. HRSC Press.

DoE (Department of Education) (2006). Funding for foundational provision in formally approved programmes: 2007/8 to 2009/10. Pretoria: Department of Education.

Dooey, P. (1999). An investigation into the predictive validity of the Battery Test as an indicator of future academic success.

Emery, J. L. (2007). A report on the predictive validity of the BMAT (2004) for $1^{\text {st }}$ year examination performance on the veterinary medicine course at the University of Cambridge. Retrieved on July 10, 2010.

Foxcroft, C. D. and R. Stumpf. (2005). What is matric for? Papers and presentations to the Umalusi and CHET seminar on "Matric: What is to be done?" Pretoria, 23 June, 8-20.

Gouws, E., Kruger, N. and Burger, S. (2010). The Adolescent. Johannesburg. Heinemann Publisher.

Kotze, M. and Griesel, L. 2008. The prediction of the academic performance of MBA Students by means of specific aptitude and competencies 6 (2). 60-96.

Mohammadi, M. (2009). The Predictive Validity of Islamic Azad University's Entrance Examination: Does Access Mean Success? The Journal of Modern Thoughts in Education Vol 4, No 4, Autumn 2009, pp. 59-72.

Nel, C., Troskie-de Bruin, C., and Bitzer, E. (2009). Student transition from school to university: possibility for a pre-university intervention. South African Journal of Higher Education 23(5), 974-991.

Pascarella, E.T., and Terenzini, P.T. (1991). How college affects students. San Francisco. Jossey-Bass.

Riggs, I. M., \& Riggs, M. L. (1990, February). A test of the validity of selected predictors of student success in a teacher education program. Paper presented at the annual meeting of the American Association of Colleges for Teacher Education, Chicago. (ERIC Document Reproduction Service No. ED324324)

Salzman, S. A. (1991). Selecting the qualified: Predictors of student teacher performance. Paper presented at the annual meeting of the Association of Teacher Educators, New Orleans. (ERIC Document Reproduction Service No. ED330672)

Shepard, L. A. (1997). The centrality of test use and consequences for test validity. Educational Measurement: Issues and Practice, 16,(8). 13- 24.

Sireci, S. G., \& Talento-Miller E. (2006). Evaluating the predictive validity of graduate management admission test scores. Educational and Psychological Measurement, 66, 305-317.

Smith, I. L., \& Hambleton, R. K. (1990). Content validity studies of licensing examinations. Educational Measurement: Issues and Practice, 9(4), 7-10. 
Stumpf, G., and Hunt, P. (2005). 'The effect of an orientation course on the retention and academic standing of entering freshmen, controlling for the volunteer effect'. Journal of freshman year experience, 22 (3), 6-11.

Tait, M. S., van Eeden, S. and Tait, M. (2002). An exploratory study on the perceptions of previously educationally disadvantaged first year learners of law regarding university education. South African Journal of Higher Education 16(2): 177-182.

Viljoen, H. (2005). Constraints in the teaching and learning of humanities at South African Universities: A Delphi study. South African Journal of Higher Education 19(1): 31-43.

Wang, H. (2004). Why teach science? Graduate science students' perceived motivation for choosing teaching as a career in Taiwan. International Journal of Science Education, 26 (1), 113-128.

Wilcox, P. (2005). It was nothing to do with the university, it was just the people: the role of social support in the first year experience of university. Studies in Higher Education, 30 (6), 19-27. 